\title{
Persistence With Lipid-Lowering Therapy: Influence of the Type of Lipid-Lowering Agent and Drug Benefit Plan Option in Elderly Patients
}

\author{
SUSAN M. ABUGHOSH, PhD; STEPHEN J. KOGUT, RPh, MBA, PhD; \\ SUSAN E. ANDRADE, ScD; E. PAUL LARRAT, RPh, MBA, PhD; and JERRY H. GURWITZ, MD
}

\begin{abstract}
OBJECTIVE: To determine the effects of lipid-lowering agent (LLA) class and drug plan design option on persistence with LLAs among elderly patients enrolled in a managed care plan.

METHODS: A retrospective cohort study was conducted among 310 older adult members enrolled in a health maintenance organization operating in New England who were dispensed an LLA between July 1, 1994, and June 30, 1996. Survival analysis was used to examine differences in discontinuation of LLAs between different classes of LLAs and drug benefit plans as well as patient sex, age, prior hospitalization for coronary heart disease (CHD), hypertension, diabetes mellitus, and the number of other medications.
\end{abstract}

RESULTS: The overall LLA discontinuation rate increased with time from $18 \%$ (95\% confidence interval [Cl], $13.8 \%-22.4 \%)$ at 6 months to $46 \%(95 \% \mathrm{Cl}, 39.7 \%$ $52.5 \%)$ at 12 months and $66 \%(95 \% \mathrm{Cl}, 59.2 \%-73.0 \%)$ at 18 months. The likelihood of discontinuation increased from $54 \%(95 \% \mathrm{Cl}, 44.8 \%-63.6 \%)$ at 12 months to $77 \%(95 \% \mathrm{Cl}, 67.5 \%-85.5 \%)$ at 18 months in nonstatin users and from $39 \%(95 \%$ $\mathrm{Cl}, 30.4 \%-47.6 \%)$ at 12 months to $57 \%(95 \% \mathrm{Cl}, 47.3 \%-66.9 \%)$ at 18 months in statin users $(P=0.001)$. Among patients prescribed a statin at initial prescription ( $\mathrm{n}=182)$, the 12-month discontinuation rates were $33 \%(95 \% \mathrm{Cl}, 23.0 \%-43.6 \%)$ for those with full drug benefit coverage and $50 \%(95 \% \mathrm{Cl}, 34.8 \%-65.1 \%)$ for those with $\$ 1,000$ per year maximum coverage, while the 21-month discontinuation rates were $60 \%(95 \% \mathrm{Cl}, 46.3 \%-72.9 \%)$ for those with full coverage and $86 \%(95 \% \mathrm{Cl}$, $73.7 \%-98.7 \%)$ for those with $\$ 1,000$ per year maximum coverage $(P=0.023)$. Adjusting for plan design and hypertension, statin users were less likely to discontinue compared with users of other LLAs (rate ratio $[\mathrm{RR}]=0.58 ; 95 \% \mathrm{Cl}, 0.40-0.82$; $P=0.002$ ). Among patients dispensed a statin, full-coverage members were less likely to discontinue compared with members having an annual $\$ 1,000$ maximum drug coverage, adjusting for diabetes and hypertension $(\mathrm{RR}=0.58 ; 95 \% \mathrm{Cl}$, 0.34-0.98; $P=0.041$ ). This finding was among a small sample after subanalyses, and further research is warranted. Plan design was not determined to be significantly associated with discontinuation of other LLAs.

CONCLUSIONS: Our findings suggest that persistence with LLAs is low among older patients regardless of scope of drug benefit coverage or the drug class. Addressing the challenges of maintaining adherence to prescribed therapeutic regimens in the elderly will require a multifaceted approach; deficiencies will not be eliminated simply through the provision of prescription drug benefit coverage.

KEYWORDS: Persistence, Lipid-lowering agents, Statins, Elderly, Drug benefit plans, Managed care

J Manag Care Pharm. 2004;10(5):404-11
$\mathrm{T}$ he cost of pharmaceuticals is among the fastest-rising components of health care costs. ${ }^{1}$ Policy responses have included limits on prescription costs, restriction on the supply of health care, and shifting of the financial risk to providers and beneficiaries. ${ }^{2-4}$ Patient cost sharing through deductibles, coinsurance, and copayments is one technique increasingly being used to contain medical costs in general, and prescription costs in particular, to deter patients from unnecessary use. $^{2-4}$ There is, however, a concern that necessary utilization could be reduced, which may, in turn, increase the risk of adverse health consequences and resulting costs. ${ }^{1-8}$

Utilization for services related to the treatment and prevention of coronary heart disease (CHD) is important to consider because CHD continues to be the leading cause of death in the U.S. population. ${ }^{9}$ Cardiovascular disease accounts for 950,000 deaths annually in the United States, including 460,000 from $\mathrm{CHD}$, and $85 \%$ of those who die from CHD are aged 65 years or older. ${ }^{9}$ The prevalence of nonfatal CHD among U.S. adults aged 40 years and above was reported to be $11.8 \%{ }^{10}$ It remains an important disease with significant burden. Estimated yearly costs for medical treatment of $\mathrm{CHD}$ and lost wages in the United States range from $\$ 50$ billion to $\$ 100$ billion. ${ }^{9,11}$

Adherence to lipid-lowering agents (LLAs) is often problematic, ${ }^{12}$ especially since hyperlipidemia may be a chronic condition perceived by the patient as not having deleterious health consequences until far into the future..$^{13}$ Reported 1-year adherence rates for LLAs range from $25 \%$ to $85 \%{ }^{14-20}$ The public health importance of adherence to LLAs is evidenced by the efficacy of these drugs in obtaining benefits in both primary ${ }^{21-24}$ and secondary ${ }^{25-27}$ prevention of CHD.

\section{Authors}

SUSAN M. ABUGHOSH, PhD, is a postdoctoral fellow, STEPHEN J. KOGUT, $R P h, M B A, P h D$, is assistant professor of pharmacoepidemiology, and E. PAUL LARRAT, RPh, MBA, PhD, is professor of pharmacoepidemiology, Pharmacoepidemiology and Pharmacoeconomics Program, University of Rhode Island, Kingston; SUSAN E. ANDRADE, $S C D$, is an assistant professor of medicine and senior research associate, and JERRY H. GURWITZ, MD, is a professor of medicine and director, Meyers Primary Care Institute, University of Massachusetts Medical School, and Fallon Foundation, both in Worcester, Massachusetts.

AUTHOR CORRESPONDENCE AND REQUEST FOR REPRINTS: SUsan M. Abughosh, PhD, Postdoctorate Fellow, Pharmacoepidemiology and Pharmacoeconomics Program, University of Rhode Island, 41 Lower College Rd., Kingston, RI 02881. Tel: (401) 431-6412; Fax: (401) 874-2181; Email: susghosh@yahoo.com

Copyright $\odot$ 2004, Academy of Managed Care Pharmacy. All rights reserved. 
Little is known about policy effects on persistence to lipid-lowering therapy among older adults. Our objectives were to explore the effects of LLA class as well as drug benefit plan options on persistence to LLAs and to identify other characteristics that predict poor persistence among older patients.

\section{Methods}

\section{Study Population and Design}

A retrospective cohort study was conducted among elderly enrollees (Medicare beneficiaries) of a 168,000-member health maintenance organization (HMO) operating in New England with approximately 17,000 members aged 65 years or older. We identified members aged 65 years or older who were continuously enrolled in the plan during the period from July 1, 1993, through June 30, 1996, and were prescribed an LLA. These members were able to choose among 3 drug benefit options starting January 1, 1994: full coverage for prescription drugs, a maximum of $\$ 1,000$ per year in coverage, or no drug coverage. There was a nominal copayment per prescription of $\$ 5$ or less that was the same for all members. Those members who selected full drug coverage paid an additional premium of $\$ 72.50$ per month ( $\$ 870$ per year). Those with $\$ 1,000$ annual maximum coverage for drugs paid an additional $\$ 39.16$ per month (\$469.92 per year). Those without drug coverage paid no additional premium.

New users of LLAs were identified by selecting patients with a prescription of an LLA between July 1, 1994, and June 30, 1996, among individuals with no prior dispensing for an LLA during the previous 12 months. The automated health plan databases were used to identify information on demographic characteristics, drug benefit plan type, prescriptions dispensed, hospitalizations, and diagnoses.

Members with greater than a 6-month period (180 days) between refills or between the last refill and the end of the study period were considered to have discontinued the drug. Switching to another type of LLA was not considered as a discontinuation. In previous research, Andrade et al. ${ }^{14}$ used a 6-month period (180 days) or more between refills to flag potential discontinuation. Jackevicius et al. ${ }^{18}$ used having a prescription every 120 days to define adherence and used 180 days for a sensitivity analysis, while Simons et al. ${ }^{16}$ used a 4-week period without collecting a prescription to define discontinuation.

The patient characteristics that we assessed included class of LLA (statin, including pravastatin, lovastatin, and fluvastatin, versus other LLAs, including bile acid sequestrants, fibrates, and niacin); drug benefit plan type (full coverage versus maximum $\$ 1,000$ per year in coverage); gender; age (below 70 and 70 years or older, based on the mean age of 70 years and frequency distribution); comorbidities, including CHD (ICD-9-CM code = 410-414.X), diabetes (ICD-9-CM code $=250 . \mathrm{X}$ ), and hypertension (ICD-9-CM code $=401-405 . X$ ); and number of other medi-

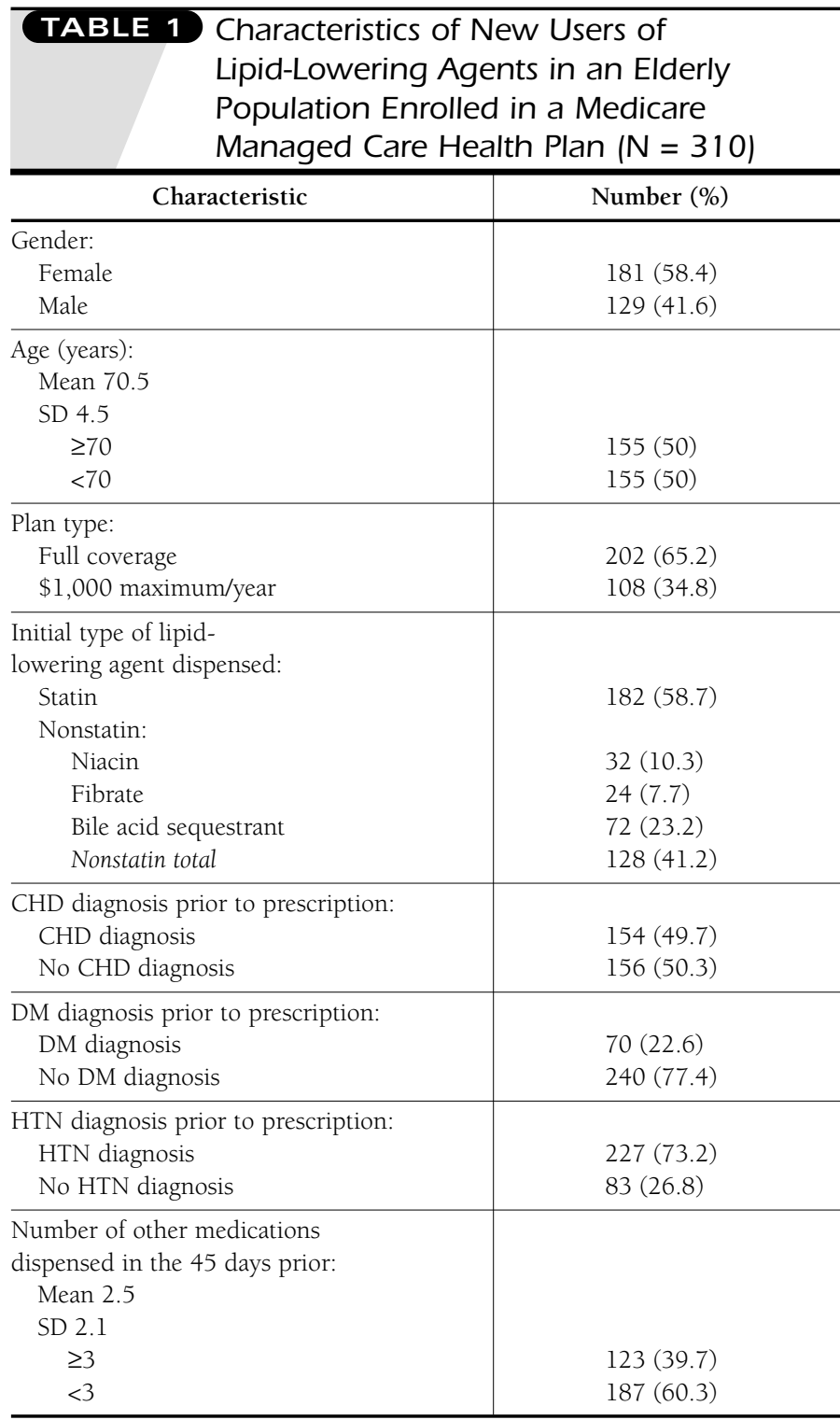

$\mathrm{SD}=$ standard deviation; $\mathrm{CHD}=$ coronary heart disease; $\mathrm{DM}=$ diabetes mellitus; HTN = hypertension.

cations dispensed in the 45-day period prior to the initial dispensing ( 0 to 2 other medications or 3 and more).

\section{Statistical Analyses}

Descriptive statistics were used to determine the frequencies of various patient characteristics. Survival analysis was used to assess the effect of drug benefit options, LLA class, and other patient characteristics on the discontinuation of LLAs.

Kaplan-Meier curves were independently constructed for each of the predictor variables, and the log-rank statistic was used to evaluate group differences. Assessment of the proportional 


\begin{tabular}{|c|c|c|c|c|c|}
\hline \multirow[b]{2}{*}{ Characteristic } & \multicolumn{2}{|c|}{$\begin{array}{l}\text { Discontinued at } \\
12 \text { months }\end{array}$} & \multicolumn{2}{|c|}{$\begin{array}{l}\text { Discontinued at } \\
18 \text { months }\end{array}$} & \multirow[b]{2}{*}{$\begin{array}{c}\text { Log Rank } \\
\text { Probability } \\
\end{array}$} \\
\hline & $\%$ & $\begin{array}{c}95 \% \\
\text { Confidence Interval }\end{array}$ & $\%$ & $\begin{array}{c}95 \% \\
\text { Confidence Interval }\end{array}$ & \\
\hline Total population & 46.1 & $39.7-52.5$ & 66.1 & $59.2-73.0$ & \\
\hline Gender: & & & & & $0.020^{*}$ \\
\hline $\begin{array}{l}\text { Female } \\
\text { Male }\end{array}$ & $\begin{array}{l}49.3 \\
40.7\end{array}$ & $\begin{array}{l}41.1-57.5 \\
30.3-51.1\end{array}$ & $\begin{array}{l}72.6 \\
55.7\end{array}$ & $\begin{array}{l}64.4-80.8 \\
44.1-67.3\end{array}$ & \\
\hline $\begin{array}{l}\text { Age (years): } \\
\quad \geq 70 \\
\quad<70\end{array}$ & $\begin{array}{l}49.1 \\
43.1\end{array}$ & $\begin{array}{l}39.9-58.3 \\
34.1-51.1\end{array}$ & $\begin{array}{l}68.1 \\
64.0\end{array}$ & $\begin{array}{l}58.7-77.5 \\
54.0-74.0\end{array}$ & 0.358 \\
\hline $\begin{array}{l}\text { Plan type: } \\
\quad \text { Full coverage } \\
\quad \$ 1,000 \text { maximum/year }\end{array}$ & $\begin{array}{l}43.1 \\
51.9\end{array}$ & $\begin{array}{l}35.2-51.0 \\
40.9-62.9\end{array}$ & $\begin{array}{l}63.0 \\
71.9\end{array}$ & $\begin{array}{l}54.3-71.7 \\
60.9-82.9\end{array}$ & 0.242 \\
\hline $\begin{array}{l}\text { Class of initial LLA: } \\
\text { Statin } \\
\text { Nonstatin LLA }\end{array}$ & $\begin{array}{l}39.0 \\
54.2\end{array}$ & $\begin{array}{l}30.4-47.6 \\
44.8-63.6\end{array}$ & $\begin{array}{l}57.1 \\
76.5\end{array}$ & $\begin{array}{l}47.3-66.9 \\
67.5-85.5\end{array}$ & $0.001^{*}$ \\
\hline $\begin{array}{l}\text { CHD diagnosis prior to prescription: } \\
\text { CHD diagnosis } \\
\text { No CHD diagnosis }\end{array}$ & $\begin{array}{l}41.7 \\
50.0\end{array}$ & $\begin{array}{l}32.4-51.0 \\
41.1-58.9\end{array}$ & $\begin{array}{l}59.8 \\
71.9\end{array}$ & $\begin{array}{l}49.5-70.1 \\
62.9-80.9\end{array}$ & 0.082 \\
\hline $\begin{array}{l}\text { DM diagnosis prior to prescription: } \\
\text { DM diagnosis } \\
\text { No DM diagnosis }\end{array}$ & $\begin{array}{l}39.1 \\
47.8\end{array}$ & $\begin{array}{l}25.0-53.2 \\
40.6-55.0\end{array}$ & $\begin{array}{l}58.8 \\
67.8\end{array}$ & $\begin{array}{l}42.3-75.3 \\
60.3-75.3\end{array}$ & 0.105 \\
\hline $\begin{array}{l}\text { HTN diagnosis prior to prescription: } \\
\text { HTN diagnosis } \\
\text { No HTN diagnosis }\end{array}$ & $\begin{array}{l}46.9 \\
43.6\end{array}$ & $\begin{array}{l}39.5-54.3 \\
30.5-56.7\end{array}$ & $\begin{array}{l}66.9 \\
63.4\end{array}$ & $\begin{array}{l}59.2-74.6 \\
48.7-78.1\end{array}$ & 0.272 \\
\hline $\begin{array}{l}\text { Number of other medications dispensed } \\
\text { in the } 45 \text { days prior: } \\
\geq 3 \\
0-2\end{array}$ & $\begin{array}{l}48.9 \\
44.2\end{array}$ & $\begin{array}{l}38.7-59.1 \\
35.9-52.5\end{array}$ & $\begin{array}{l}68.5 \\
64.5\end{array}$ & $\begin{array}{l}57.8-79.2 \\
55.6-73.4\end{array}$ & 0.443 \\
\hline
\end{tabular}

* Significant result $P<0.05 . L L A=$ lipid-lowering agent; $C H D=$ coronary heart disease; $D M=$ diabetes mellitus; $H T N=$ hypertension.

hazards assumption for each of the predictor variables was carried out, and stratification was used for hypertension where this assumption was violated.

Cox proportional hazards models were used to estimate rate ratios (RR) and 95\% confidence intervals (CI) for the association between patient characteristics and LLA discontinuation. Persistence to LLAs has been previously examined using Cox proportional hazards models. ${ }^{16,18}$ Backward elimination was used to construct the final models that included the variable plan type and any other significant variables. All statistical analyses were performed using SAS statistical package version 8.01.

\section{Results}

A total of 2,229 patients, which was approximately $13 \%$ of the elderly health plan members, were continuously enrolled between July 1, 1993, and June 30, 1996, and received an LLA prescription during this time period. Of those patients, 1,793
(80.4\%) had an LLA prescription between July 1, 1994, and June 30, 1996. We identified 475 new users of LLAs (21.3\% of the total) by omitting patients with an LLA prescription in the previous year (between July 1, 1993, and June 30, 1994). We omitted 153 patients with the initial LLA prescription after January 1, 1996, in order to have a 6-month or longer observation period for all subjects. Thus, a total of 322 patients met our inclusion criteria. We omitted 12 patients having no drug coverage because of the low number in this category. The final study population was composed of 310 patients. Baseline characteristics are presented in Table 1 . The mean age of these patients was 70.5 years and $58 \%$ were female. There were more subjects in the full coverage drug benefit plan $(n=202,65.2 \%)$ than in the plan with $\$ 1,000$ annual maximum drug coverage $(n=108,34.8 \%)$.

Statins were the most widely dispensed LLA, with $59 \%$ of patients dispensed a statin as the initial LLA. Approximately 
half of the patient population was hospitalized for CHD prior to the initial LLA prescription $(\mathrm{n}=154,49.7 \%)$.

Table 2 presents the discontinuation rates at 12 months and 18 months, overall and according to patient characteristics. Overall discontinuation increased with time from $18.1 \%(95 \%$ CI, $13.8 \%-22.4 \%)$ at 6 months to $46.1 \%$ (95\% CI, 39.7\%-52.5\%) at 12 months and $66.1 \%$ (95\% CI, 59.2\%-73.0\%) at 18 months. Drug plan type was not associated with discontinuation $(P=$ 0.242 ) (Figure1). Females were more likely to discontinue than males $(P=0.020)$. A significant difference also existed between statin and nonstatin LLA users $(P=0.001)$. The likelihood of discontinuation increased from $22.7 \%$ (95\% CI, 15.4\%-29.9\%) at 6 months to $54.2 \%(95 \% \mathrm{CI}, 44.8 \%-63.6 \%)$ at 12 months and $76.5 \%$ (95\% CI, 67.5\%-85.5\%) at 18 months in nonstatin users and from $14.8 \%(95 \% \mathrm{CI}, 9.6 \%-20.0 \%)$ at 6 months to $39.0 \%(95 \% \mathrm{CI}, 30.4 \%-47.6 \%)$ at 12 months and $57.1 \%(95 \%$ CI, $47.3 \%-66.9 \%)$ at 18 months in statin users.

Among patients prescribed a statin at initial prescription $(\mathrm{n}=182)$, the 6 month discontinuation rates were $11.5 \%(95 \%$ $\mathrm{CI}, 5.8 \%-17.1 \%$ ) for full coverage plan members (with no annual maximum) and $21.7 \%$ (95\% CI, 11.3\%-32.1\%) for the members with annual $\$ 1,000$ maximum coverage, while the 12 -month discontinuation rates were 33.3\% (95\% CI, 23.0\%$43.6 \%$ ) for those with full coverage and $50.0 \%$ (95\% CI, 34.8\%$65.1 \%$ ) for those with a maximum of $\$ 1,000$ per year coverage. These rates increased to $49.2 \%$ (95\% CI, 36.9\%-61.6\%) at 18 months and to $59.6 \%$ (95\% CI, 46.3\%-72.9\%) at 21 months for those with full coverage, compared with $71.4 \%$ (95\% CI, $56.4 \%-86.4 \%$ ) at 18 months and $86.2 \%$ (95\% CI, 73.7\%$98.7 \%$ ) at 21 months for those with a $\$ 1,000$ per year maximum coverage (Figure 2). The difference was statistically significant $(P=0.023)$.

For patients prescribed nonstatin lipid-lowering agents at initial prescription, the discontinuation rates were $21.3 \%$ (95\% CI, $12.3 \%-30.2 \%)$ at 6 months, $54.3 \%$ (95\% CI, $42.6 \%-66.0 \%)$ at 12 months, and $78.6 \%$ (95\% CI, $67.8 \%-89.3 \%)$ at 18 months among full-coverage patients. These rates were 25\% (95\% CI, $12.8 \%-37.3 \%)$ at 6 months, $54.1 \%(95 \%$ CI, 38.0\%-70.1\%) at 12 months, and $72.4 \%$ (95\% CI, 56.1\%-88.7\%) at 18 months among those with an annual maximum of $\$ 1,000$ coverage. The difference was not statistically significant $(P=0.467)$.

In the final models, those dispensed statin LLAs were less likely to discontinue as compared with users of nonstatin LLAs, adjusting for plan type and hypertension $(\mathrm{RR}=0.58 ; 95 \% \mathrm{CI}$, 0.40-0.82; $P=0.002$ ). Among patients dispensed a statin at initial prescription, full-coverage members were less likely to discontinue compared with members with annual $\$ 1,000$ maximum coverage, adjusted for diabetes and hypertension $(\mathrm{RR}=0.58 ; 95 \% \mathrm{CI}, 0.34-0.98 ; P=0.041)$. Those with diabetes were less likely to discontinue than those without diabetes $(\mathrm{RR}=0.37 ; 95 \% \mathrm{CI}, 0.16-0.86 ; P=0.020$ ).

Plan type was not determined to be significantly associated
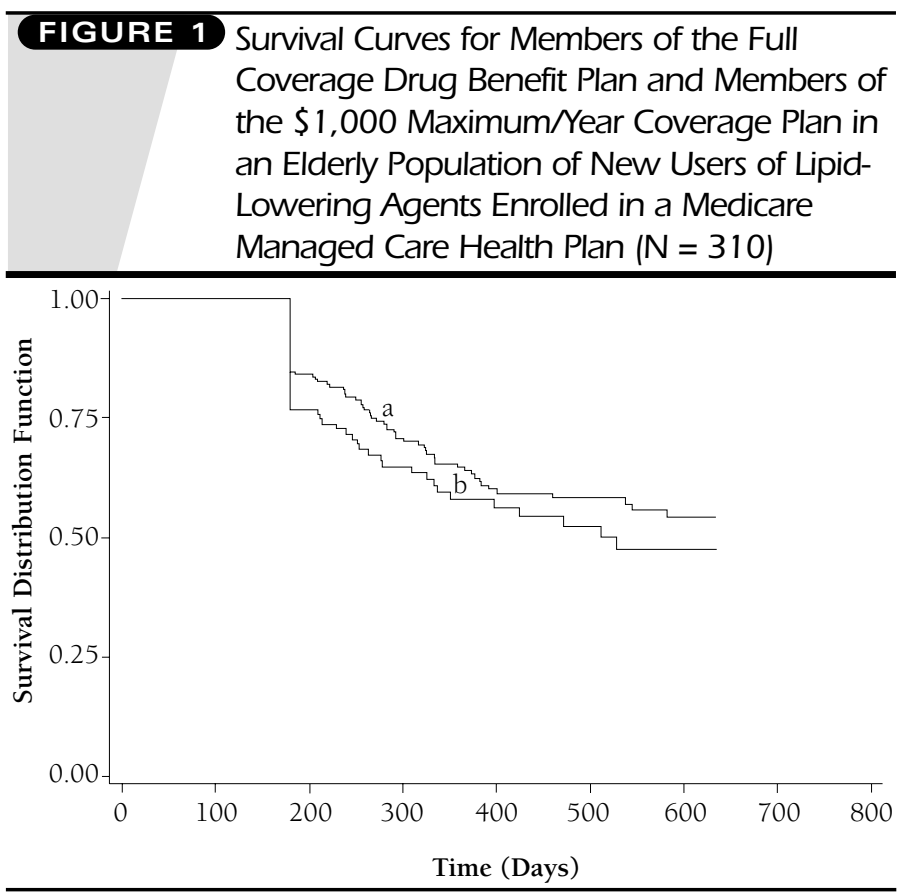

$a=$ full coverage plan members (no annual maximum).

$b=\$ 1,000$ maximum/year-coverage plan members.

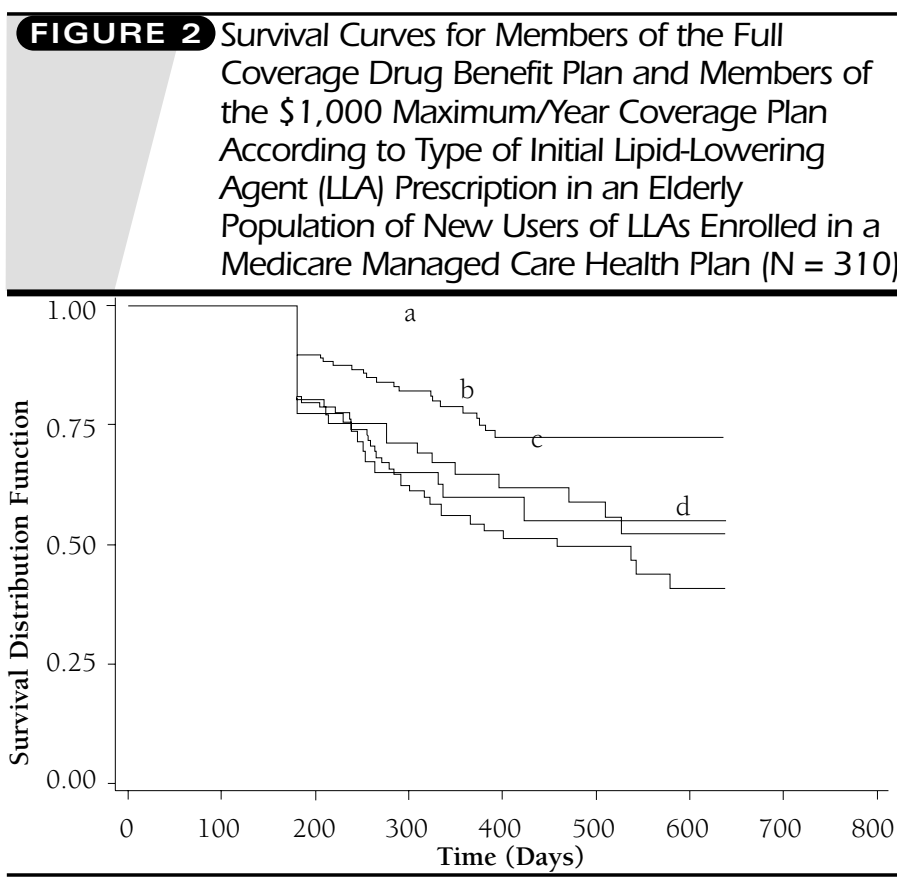

$a=$ full coverage (no annual maximum) plan members dispensed a statin at initial prescription.

$b=\$ 1,000$ maximum/year-coverage plan members dispensed a statin at initial prescription.

$c=\$ 1,000$ maximum/year-coverage plan members dispensed other LLAs at initial prescription.

$d=$ full coverage (no annual maximum) plan members dispensed other LLAs at initial prescription. 


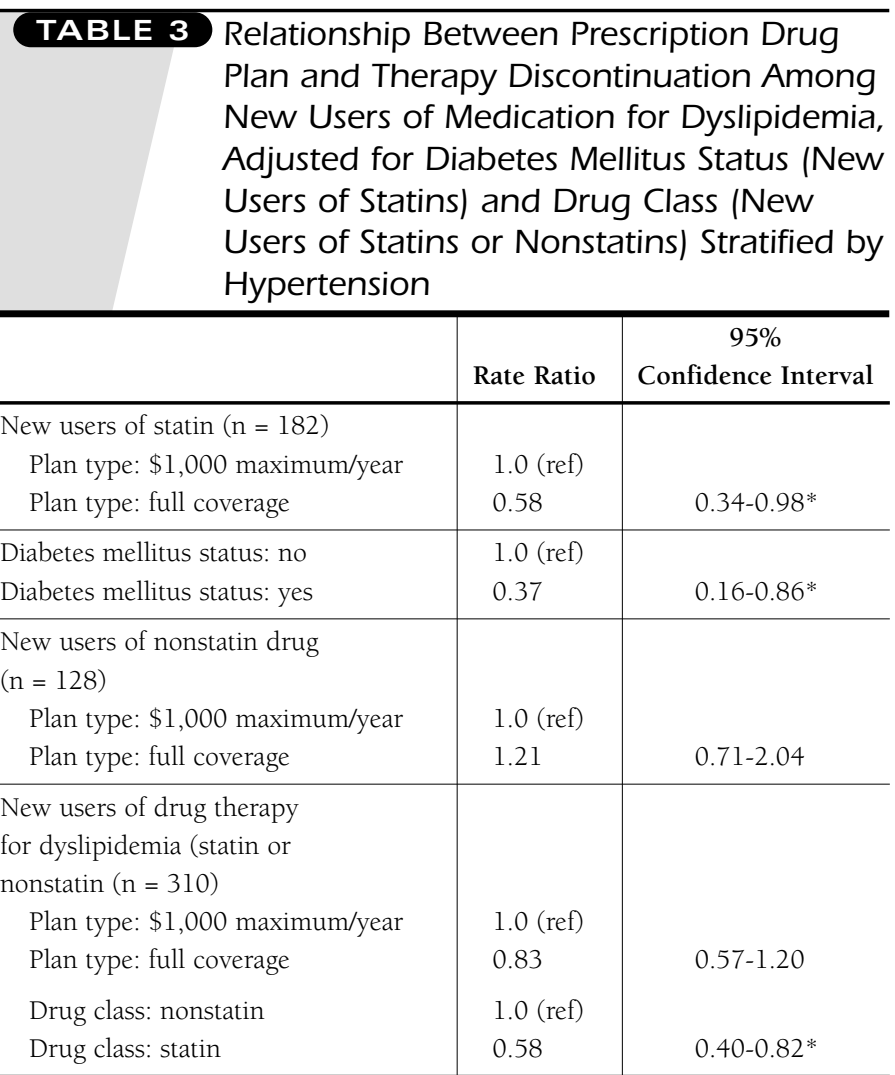

* Significant difference (chi-square probability <0.05).

Ref = reference group.

with discontinuation of other LLAs. No significant differences in persistence rate existed with gender, age, CHD, diabetes, and number of medications. These results are presented in Table 3.

\section{Discussion}

Our findings suggest that discontinuation rates for LLAs are high, as previously reported, ${ }^{14,16,18-20}$ and indicate better persistence with statins as compared with other types of LLAs. Among members dispensed a statin at initial prescription, those with full drug benefit coverage were less likely to discontinue than members with an annual maximum drug benefit coverage of $\$ 1,000$. We did not find the level of pharmacy benefit selected by enrollees to be associated with the likelihood of discontinuing nonstatin LLA drug therapy.

The study documented a 1-year LLA discontinuation rate of $46 \%$, which was higher than the discontinuation rates reported in clinical trials (ranging from $4 \%$ to $15 \%$ ) and by Andrade et al. (32\%). ${ }^{14}$ In an Australian practice setting, a 60\% discontinuation rate over 1 year was reported. ${ }^{16}$ For statins, the 1 -year discontinuation rate was found to be $39 \%$, higher than that reported by
Andrade et al. (15\% for lovastatin) $)^{14}$ and lower than that reported in other studies, which ranged from $52 \%$ to $61 \%$. $16,19,20$

We found that discontinuation increased progressively with duration of treatment, consistent with the findings from other studies. ${ }^{12,18,19}$ We noticed that the increase in discontinuation slowed after the first year.

The cost of medications has been cited among factors contributing to nonadherence in the elderly. ${ }^{28}$ Medicare patients who do not have prescription drug coverage are reported to face higher out-of-pocket expenditures and are more likely to let prescriptions go unfilled. ${ }^{29}$ Elderly Medicare beneficiaries with CHD who lack drug coverage were shown to have significantly lower rates of statin drug use (4.1\%) compared with those with drug coverage (27.4\%) in a nationally representative sample of Medicare beneficiaries. ${ }^{30}$ Furthermore, Medicare beneficiaries with capped dollar amounts on prescriptions have been reported to take steps to decrease their out-of-pocket prescription costs, including discontinuing the prescribed medication. ${ }^{31}$ In a national survey of 4,896 older adults aged 70 years or older who regularly took prescribed medications, medication restriction was reported in $8 \%$ of subjects with no coverage, $3 \%$ of those with partial coverage and, $2 \%$ with full coverage ( $P<0.01$ for trend). ${ }^{6}$ At the same time, there appears to be no consensus regarding the impact of patient copayments on therapy persistence, ${ }^{32,33}$ and evidence that higher copayments for prescription medications result in clinically significant discontinuation rates is currently lacking. ${ }^{34,35}$

In our study, the drug benefit plan option (design) was found to be associated with persistence among statin users. A possible explanation for this finding is that some patients with the limited drug benefit option discontinued statin medications once their benefit limit was met. This finding, however, was among a small sample after subanalyses, thus further research is needed to evaluate the effect of drug benefits on persistence. No association was found between drug benefit plan design and persistence among users of other (nonstatin) LLAs.

Medication adherence in older adult patients, in general, is of particular concern because they may exhibit an increased susceptibility to adverse event ${ }^{36}$ due to deficits in physical dexterity, cognitive skills, and memory and the large number of medications they are prescribed. ${ }^{37}$ Previous research on elderly patients taking LLAs specifically has shown high discontinuation rates in patients with drug coverage. ${ }^{15,18,19}$ Benner et al. ${ }^{19}$ found a $43 \%$ persistence of statin therapy in 6 months, and only 1 in 4 patients were adherent in 5 years. Jackevicius et al. found a 2-year adherence rate of $36.1 \%$ in patients with coronary artery disease and $25.4 \%$ in patients of primary prevention (without CHD). Avorn et al..$^{15}$ found that patients failed to fill their LLA prescriptions about $40 \%$ of the time over 1 year. In addition, a study in British Columbia, where there are various levels of coverage provided by the provincial government, found no significant difference between adherent and nonadherent 
patients with respect to type of provincial drug benefit coverage..$^{38}$ Our findings suggest that drug benefit cost subsidized through a drug benefit plan is not enough to guarantee persistence since we found high discontinuation rates regardless of the type of coverage.

Statin use was associated with better persistence compared with nonstatin LLAs. Adherence to lipid-lowering therapy has been previously associated with receiving a statin ${ }^{15,16,18}$ because statins are generally more tolerable than other LLAs ${ }^{39}$ and side effects have been commonly cited as reasons for noncompliance. ${ }^{14}$

The gender of the patient was not associated with discontinuation after adjustment for other patient characteristics. Results in previous studies have been inconsistent with regard to gender effects on adherence. ${ }^{28}$ Our results indicate no association even though a trend of better persistence among males was suggested by the data.

Previous hospitalization for CHD was not associated with discontinuation. Although studies have indicated better adherence to lipid-lowering drugs in secondary prevention compared with primary prevention, ${ }^{12,15,18,40}$ a number of these studies did not examine financial effects since patients were covered for the price of the drug except for a small copayment in some cases. ${ }^{15,18,19}$ Furthermore, research has shown that targeting patients during a hospitalization for an acute event or intervention procedure can improve persistence, ${ }^{41-43}$ and current National Cholesterol Education Program (NCEP) Adult Treatment Panel III guidelines recommend initiating lipidlowering drug therapy at hospital discharge..$^{41,44}$ In our study, we looked for a previous hospitalization prior to the prescription date, but we could not tell if the prescription was given while the patients were in the hospital or some time after discharge. Studies have, however, indicated that compliance with NCEP guidelines is frequently suboptimal. .5-47 $^{-4}$

The presence of diabetes and hypertension has been previously associated with better persistence among patients with dyslipidemia. ${ }^{15,18,19}$ Lower compliance with comorbidities has also been reported, possibly related to a more complex drug regimen that may be associated with comordities. ${ }^{48}$ The asymptomatic nature of hyperlipidemia may also contribute to the lower adherence to LLAs when a symptomatic comorbidity like diabetes exists. ${ }^{48}$ We did not find such associations between LLA discontinuation and these comorbidities overall. However, among patients prescribed a statin at initial prescription, we observed better persistence among diabetic patients compared with nondiabetic patients, consistent with previous reports. ${ }^{18,19}$

Previous studies have been inconsistent with regard to the effect of the number of medications $s^{15,18,19,49}$ and age ${ }^{18,19,38,48}$ on persistence. Some have even reported lower adherence with fewer medications,$^{38}$ possibly because patients prescribed a greater number of medications are presumed to be less healthy and may be more attentive to taking their drug therapy. ${ }^{38}$ We did not find a significant association between the number of other medications and persistence to LLAs.

\section{Limitations}

Several limitations to this study can be described. Regarding the data set used, patients may fill their prescriptions from pharmacies outside the HMO network, and these prescriptions will not be captured. This, however, is unlikely since the drugs were provided at discounted prices for patients in these pharmacies, and the assumption that patients fill most prescriptions within the pharmacy system under study has been confirmed in $1 \mathrm{HMO}$ and 2 Veterans Affairs medical centers ${ }^{49}$ Also, filling the prescription does not ensure that the medication is actually consumed. Yet, patterns of prescription filling represent the most feasible way of estimating actual medication use in large populations. ${ }^{15}$ We were unable to account for non-prescription drug use. For example, niacin could be obtained without a prescription. We were also unable to conduct medical chart reviews to validate information obtained from computerized data.

Other limitations include lack of comprehensive clinical data, including lipid levels and exact reasons for LLA discontinuation. We were unable to control for some potential confounders that have been reported to affect adherence such as race, ${ }^{19,28}$ regimen complexity ${ }^{48}$ side effects, ${ }^{14}$ and perceived health. ${ }^{15}$ We also do not have information on income levels, coinsurance, or education levels for our population cohort. We could not account for use of samples or hospitalizations during a follow-up period. However, we believe that our criterion of 6 months without a prescription being dispensed to be classified as nonpersistent mitigates the potential influence of these factors because it would be difficult to obtain drug samples that cover such a long period of time and it is a long period for a continuous hospitalization.

\section{Conclusions}

We found high rates of discontinuation among users of LLAs regardless of type of LLA (statin or other) or drug benefit plan design. These findings emphasize the importance of research and the development of interventions to improve persistence to these medications. With the recent enactment of a voluntary Medicare "Part D" benefit providing some coverage for prescription drugs, one goal of which is to reduce financial barriers that might prevent beneficiaries from obtaining needed drugs, ${ }^{51}$ one must consider that many patients will still discontinue their medication. Improving patient understanding of cardiovascular risk, medication regimens, and the benefits of persistence is expected to enhance adherence to LLAs. ${ }^{12}$ To achieve the desired benefit of drug therapy, long-term commitment to patient education, monitoring, and reinforcement with a multidisciplinary approach, including pharmacists, nurses, physicians and dieticians, is warranted. ${ }^{12,19,50}$

\section{ACKNOWLEDGMENTS}

The authors thank Jackie Cernieux Fuller, MPH, programmer, Meyers Primary Care Institute, 425 North Lake Ave., Worcester, MA, for her technical assistance in extracting the data for analysis. 


\section{DISCLOSURES}

Funding for this research was provided by the Geriatric Drug Therapy and Research Institute of the American Society of Consultant Pharmacists and was obtained by author Jerry H. Gurwitz. Gurwitz and authors Susan M. Abughosh, Stephen J. Kogut, Susan E. Andrade, and E. Paul Larrat disclose no bias or conflict of interest relating to this article. Abughosh served as principal author of the study. Study concept and design and analysis and interpretation of data were contributed by all authors. Drafting of the manuscript was primarily the work of Abughosh, and its critical revision was the work of Kogut, Andrade, Larrat, and Gurwitz. Statistical expertise was contributed by Abughosh, Kogut, Andrade, and Larrat.

\section{REFERENCES}

1. Steinwachs DM. Pharmacy benefit plans and prescription drug spending. JAMA. 2002;288:1773-74.

2. Johnson RE, Goodman MJ, Hornbrook MC, Eldredge MB. The effect of increased prescription drug cost-sharing on medical care utilization and expenses of elderly health maintenance organization members. Med Care. 1997;35:1119-31.

3. Johnson RE, Goodman MJ, Hornbrook MC, Eldredge MB. The impact of increasing patient prescription drug cost sharing on therapeutic classes of drugs received and on the health status of elderly HMO members. Health Serv Res. 1997;32:103-22.

4. Levy RA. Prescription cost sharing:economic and health impacts, and implications for health policy. Pharmacoeconomics. 1992;2:219-37.

5. Tamblyn R, Laprise R, Hanley JA, et al. Adverse events associated with prescription drug cost-sharing among poor and elderly persons. JAMA 2001;285:421-29.

6. Steinman MA, Sands LP, Covinsky KE. Self-restriction of medications due to cost in seniors without prescription coverage. J Gen Intern Med. 2001; 16:793-99.

7. Soumerai SB, Avorn J, Ross-Degnan D, Gortmaker S. Payment restrictions for prescription drugs under Medicaid. Effects on therapy, cost, and equity. N Engl J Med. 1987;317:550-56.

8. Soumerai SB, Ross-Degnan D, Fortess EE, Abelson J. A critical analysis of studies of state drug reimbursement policies:research in need of discipline. Milbank Q. 1993;71:217-52.

9. American Heart Association. 2001 Heart and Stroke Statistical Update. Dallas, TX: American Heart Association; 2001:11.

10. Ford ES, Giles WH, Croft JB. Prevalence of nonfatal coronary heart disease among American adults. Am Heart J. 2000;139:371-77.

11. Summary of The Second Report of the National Cholesterol Education Program (NCEP) Expert Panel on Detection, Evaluation, and Treatment of High Blood Cholesterol in Adults (Adult Treatment Panel II). JAMA. 1993;269:3015-23.

12. Insull W. The problem of compliance to cholesterol altering therapy. J Intern Med. 1997;241:317-25.

13. LaRosa JH, LaRosa JC. Enhancing drug compliance in lipid-lowering treatment. Arch Fam Med. 2000;9:1169-75.

14. Andrade SE, Walker AM, Gottlieb LK, et al. Discontinuation of antihyperlipidemic drugs-do rates reported in clinical trials reflect rates in primary care settings? N Engl J Med. 1995;332:1125-31.

15. Avorn J, Monette J, Lacour A, et al. Persistence of use of lipid-lowering medications:a cross-national study. JAMA. 1998;279:1458-62.

16. Simons LA, Levis G, Simons J. Apparent discontinuation rates in patients prescribed lipid-lowering drugs. Med J Aust. 1996;164:208-11.

17. Eriksson M, Hadell K, Holme I, Walldius G, Kjellstrom T. Compliance with and efficacy of treatment with pravastatin and cholestyramine:a randomized study on lipid-lowering in primary care. J Intern Med. 1998;243:373-80.

18. Jackevicius CA, Mamdani M, Tu JV. Adherence with statin therapy in elderly patients with and without acute coronary syndromes. JAMA. 2002;288:462-67.
19. Benner JS, Glynn RJ, Mogun H, Neumann PJ, Weinstein MC, Avorn J. Long-term persistence in use of statin therapy in elderly patients. JAMA. 2002;288:455-61

20. O'Connor PJ, Rush WA, Trence DL. Relative effectiveness of niacin and lovastatin for treatment of dyslipidemias in a health maintenance organization. J Fam Pract. 1997;44:462-67.

21. Shepherd J, Cobbe SM, Ford I, et al. Prevention of coronary heart disease with pravastatin in men with hypercholesterolemia. West of Scotland Coronary Prevention Study Group. N Engl J Med. 1995;333:1301-07.

22. Downs JR, Clearfield M, Weis S, et al. Primary prevention of acute coronary events with lovastatin in men and women with average cholesterol levels:results of AFCAPS/TexCAPS. Air Force/Texas Coronary Atherosclerosis Prevention Study. JAMA. 1998;279:1615-22.

23. The Lipid Research Clinics Coronary Primary Prevention Trial results. I. Reduction in incidence of coronary heart disease. JAMA. 1984;251:351-64.

24. Frick MH, Heinonen OP, Huttunen JK, Koskinen P, Manttari M, Manninen $\mathrm{V}$. Efficacy of gemfibrozil in dyslipidaemic subjects with suspected heart disease. An ancillary study in the Helsinki Heart Study frame population. Ann Med. 1993;25:41-45.

25. Randomised trial of cholesterol lowering in 4,444 patients with coronary heart disease:the Scandinavian Simvastatin Survival Study (4S). Lancet. 1994; 344:1383-89.

26. Sacks FM, Pfeffer MA, Moye LA, et al. The effect of pravastatin on coronary events after myocardial infarction in patients with average cholesterol levels. Cholesterol and Recurrent Events Trial investigators. N Engl J Med. 1996;335:1001-09.

27. Prevention of cardiovascular events and death with pravastatin in patients with coronary heart disease and a broad range of initial cholesterol levels. The Long-Term Intervention with Pravastatin in Ischaemic Disease (LIPID) Study Group. N Engl J Med. 1998;339:1349-57.

28. Balkrishnan R. Predictors of medication adherence in the elderly. Clin Ther. 1998;20:764-71.

29. Stein N. Prescription drug coverage for people with Medicare [issue brief]. Cent Medicare Educ. 2002;3:1-8

30. Federman AD, Adams AS, Ross-Degnan D, Soumerai SB, Ayanian JZ. Supplemental insurance and use of effective cardiovascular drugs among elderly medicare beneficiaries with coronary heart disease. JAMA. 2001;286: 1732-39.

31. Cox ER, Jernigan C, Coons SJ, Draugalis JL. Medicare beneficiaries' management of capped prescription benefits. Med Care. 2001;39:296-301.

32. Wogen J, Frech F. Measuring adherence to antihypertensive drug therapy [letter]. J Manag Care Pharm. 2004;10(1):88-89.

33. Curtiss FR. Does member cost sharing pose a threat to desirable patient outcomes? J Manag Care Pharm. 2004;10(2):166-67.

34. Wogen J, Frech F. Patient adherence with hypertension medication [letter]. J Manag Care Pharm. 2004;10(1):90-91.

35. Curtiss FR. 3-Tier drug benefit designs based on sound drug formulary principles will maximize favorable outcomes. J Manag Care Pharm. 2004;10(1): 83-84.

36. Monane M, Matthias DM, Nagle BA, Kelly MA. Improving prescribing patterns for the elderly through an online drug utilization review intervention: a system linking the physician, pharmacist, and computer. JAMA. 1998; 280:1249-52.

37. Cramer JA. Enhancing patient compliance in the elderly. Role of packaging aids and monitoring. Drugs Aging. 1998;12:7-15

38. Shalansky SJ, Levy AR. Effect of number of medications on cardiovascular therapy adherence. Ann Pharmacother. 2002;36:1532-39.

39. Lipsy RJ. Overview of pharmacologic therapy for the treatment of dyslipidemia. J Manag Care Pharm. 2003;9(1)(suppl):9-12.

40. Tsuyuki RT, Bungard TJ. Poor adherence with hypolipidemic drugs: a lost opportunity. Pharmacotherapy. 2001;21:576-82. 
41. Applegate WB. Elderly patients' adherence to statin therapy. JAMA. 2002; 288:495-97.

42. Hunninghake DB. Postdischarge lipid management of coronary artery disease patients according to the new National Cholesterol Education Program guidelines. Am J Cardiol. 2001;88:37K-41K.

43. Muhlestein JB, Horne BD, Bair TL, et al. Usefulness of in-hospital prescription of statin agents after angiographic diagnosis of coronary artery disease in improving continued compliance and reduced mortality. Am J Cardiol. 2001;87:257-61.

44. Executive Summary of The Third Report of The National Cholesterol Education Program (NCEP) Expert Panel on Detection, Evaluation, And Treatment of High Blood Cholesterol In Adults (Adult Treatment Panel III). JAMA. 2001;285:2486-97.

45. Dubey AK. Using rough sets, neural networks, and logistic regression to predict compliance with cholesterol guidelines goals in patients with coronary artery disease. Proc AMIA Symp. 2003:834.
46. Maviglia SM, Teich JM, Fiskio J, Bates DW. Using an electronic medical record to identify opportunities to improve compliance with cholesterol guidelines. J Gen Intern Med. 2001;16:531-37.

47. McBride P, Schrott HG, Plane MB, Underbakke G, Brown RL. Primary care practice adherence to National Cholesterol Education Program guidelines for patients with coronary heart disease. Arch Intern Med. 1998;158:1238-44.

48. Sung JC, Nichol MB, Venturini F, Bailey KL, McCombs JS, Cody M. Factors affecting patient compliance with antihyperlipidemic medications in an HMO population. Am J Manag Care. 1998;4:1421-30.

49. Steiner JF, Prochazka AV. The assessment of refill compliance using pharmacy records:methods, validity, and applications. J Clin Epidemiol. 1997;50: 105-16.

50. Anonymous. Patient compliance. Annals Pharmacother. 1993;27:S5-S19.

51. Pauly MV. The new Medicare drug benefit: much ado about little? LDI Issue Brief. 2004;9:1-6. 